\title{
Antimicrobial resistance and plasmid profiles of urinary Escherichia coli isolates from Jordanian patients
}

A.A. Shehabi, ${ }^{1}$ A.M. Mahafzah ${ }^{1}$ and K.Z. Al-Khalili'

$$
\begin{aligned}
& \text { مقاومة مضادات المكروبات ومُوتُسَمَات البلاسميدات في مستفردات الإشريكيات القولونية من المرضى } \\
& \text { الأردنيّين مضنين } \\
& \text { عاصم الشهابي، عزمي محافظة، خالد الخليلي }
\end{aligned}
$$

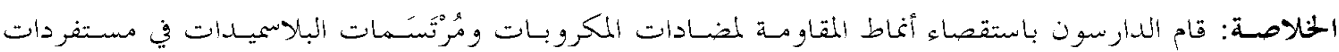

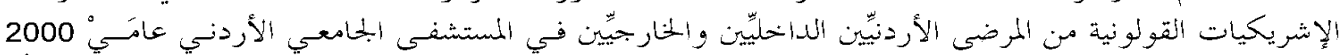

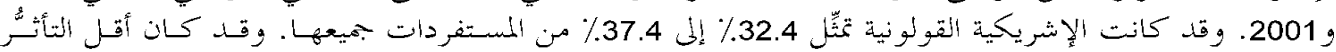

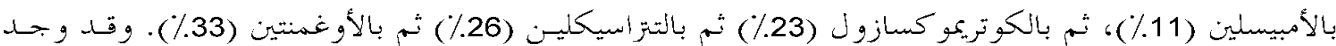

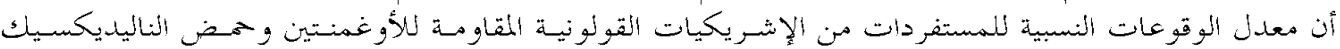

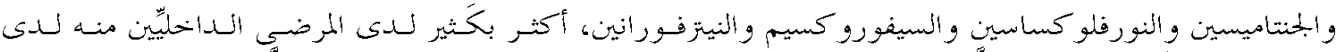

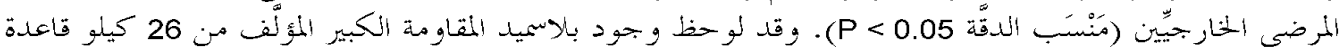

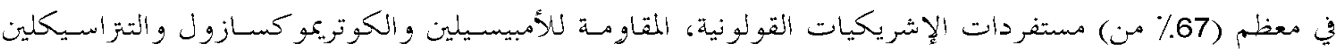

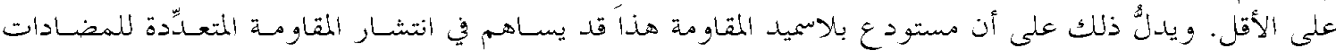

$$
\begin{aligned}
& \text { الحيوية في إقليمنا. }
\end{aligned}
$$

ABSTRACT We investigated antimicrobial resistance patterns and plasmid profiles of uropathogenic Escherichia coli isolates from inpatients and outpatients at Jordan University Hospital in 2000 and 2001. E. coli accounted for $32.4 \%$ and $37.4 \%$ of all isolates respectively. The lowest susceptibility was for ampicillin (11\%), cotrimoxazole $(23 \%)$ and tetracycline $(26 \%)$. The relative incidence of resistant isolates of $E$. coli to nalidixic acid, gentamicin, norfloxacin, cefuroxime and nitrofurantoin was significantly greater for inpatients than for outpatients $(P<0.05)$. A large, transferable R-plasmid of $28 \mathrm{~kb}$ was found in most $E$. coli isolates $(67 \%)$ that were resistant to at least ampicillin, cotrimoxazole and tetracycline. This R-plasmid reservoir may contribute to the spread of multiple antibiotic resistance in our Region.

\begin{abstract}
Résistance aux antimicrobiens et profils plasmidiques des isolats urinaires d'Escherichia coli de patients jordaniens

RESUME Nous avons étudié la résistance aux antimicrobiens et les profils plasmidiques des isolats d'Escherichia coli uropathogénique chez des malades hospitalisés et des malades externes à l'Hôpital universitaire jordanien en 2000 et 2001. E. coli représentait $32,4 \%$ et $37,4 \%$ de tous les isolats. La sensibilité la plus faible concernait l'ampicilline (11\%), le cotrimoxazole (23\%) et la tétracycline (26\%). L'incidence relative des isolats d' $E$. coli résistants à l'acide nalidixique, à la gentamicine, à la norfloxacine, à la céfuroxime et à la nitrofurantoïne était significativement plus élevée chez les malades hospitalisés que chez les malades externes $(p<0,05)$. On a trouvé un grand plasmide $\mathrm{R}$, de $28 \mathrm{~kb}$, dans la plupart des isolats d'E. coli $(67 \%)$ qui étaient résistants à l'ampicilline, au cotrimoxazole et à la tétracycline tout au moins. Ce réservoir de plasmide $\mathrm{R}$ peut contribuer à la propagation de l'antibiorésistance multiple dans notre Région.
\end{abstract}

${ }^{1}$ Department of Pathology and Microbiology, Faculty of Medicine, University of Jordan, Amman, Jordan. Received: 27/01/03; accepted: 06/05/03

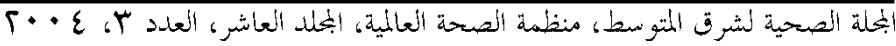




\section{Introduction}

Urinary tract infections occur in all age groups and are caused by a wide variety of pathogens with antimicrobial susceptibility patterns that have changed over time [1-6]. Increased age of patients and presence of underlying disease or immunosuppressed conditions render hospitalized patients susceptible to urinary tract infections with multiresistant bacterial strains [7-9].

Worldwide, Escherichia coli is still the most common causative microorganism of urinary tract infection, accounting for $30 \%-70 \%$ of all uropathogens [1-9]. Many recent studies from Europe and North America and a few from Arab countries have documented the development of resistance to fluoroquinolones among uropathogenic E. coli isolates [1-14].

The aim of our study was to investigate prospectively antimicrobial resistance patterns and plasmid profiles of uropathogenic E. coli isolates simultaneously from community and hospitalized patients at a major teaching hospital in Jordan.

\section{Methods}

In the first phase of our study, we collected the culture results of all midstream urine specimens submitted to the clinical bacteriology laboratory at the Jordan University Hospital in Amman for culture and susceptibility testing from January 2000 to December 2001. Specimens were cultured on MacConkey and blood agar (Oxoid, Basingstoke, UK) plates and incubated for 24 hours at $37^{\circ} \mathrm{C}$. Bacterial species were identified using standard biochemical tests [15]. Urine cultures, mostly midstream, were recorded as positive if their bacterial growth showed the presence of $>10^{5}$ colony forming units $/ \mathrm{mL}$ unless clinical data in- dicated urinary tract infection, in which case urine cultures with lower counts $\left(10^{2}-\right.$ $10^{4}$ colony forming units $/ \mathrm{mL}$ ) were also included. Positive cultures were submitted for antibiotic susceptibility using the disk diffusion method and results were expressed as susceptible or resistant according to the National Committee for Clinical Standards guidelines of 1997 [16].

The second phase of our study included 53 of 160 representative multidrugresistant $E$. coli single isolates that were randomly obtained from positive urine cultures of inpatients (23 isolates) and outpatients (22 isolates) of all age groups. Isolates were multidrug resistant if they displayed resistance to 3 or more different antibiotic classes. Eight to 10 colonies of each pure culture of $E$. coli were taken and inoculated in $1 \mathrm{~mL}$ of brain-heart infusion broth (Oxoid, Basingstoke, UK) containing $40 \%$ glycerol and then stored at $-20{ }^{\circ} \mathrm{C}$ for further investigation.

We included 53 multidrug-resistant $E$. coli isolates that were susceptible to nalidixic acid in conjugation experiments using 2 methods $[17,18]$; the recipient $E$. coli strain (K-12) was resistant to nalidixic acid only. All isolates and control strains were tested for antibiotic susceptibility prior to use. Minimum inhibitory concentrations (MICs) were determined by the agar dilution method [16]. Serial 2-fold dilutions of antibiotics were made in Mueller-Hinton agar (Difco, USA). E. coli ATCC 25922 (Difco, USA) was the standard control strain throughout the study.

We used 2 methods for the extraction of plasmid DNA: the alkaline lysis method of Birnboim and Doly [19] and the DNA purification system, A7500 (Promega, Madison, Wisconsin, USA). Plasmid DNA and lambda DNA marker were restricted by Hind III restriction enzyme. Gel electro-

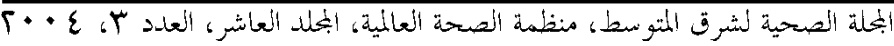


phoresis using $0.7 \%$ agarose was run for 2 hours at 95 volts in horizontal electrophoresis apparatus.

All data were entered in a computer database and analysed with SPSS software to compare variables, using 2-tailed paired samples and Student $t$-test with a significant cut-off value of 0.05 .

\section{Results}

Table 1 shows the distribution of $E$. coli isolates from urine cultures examined in the clinical bacteriology laboratory of Jordan University Hospital. A total of 3583 of 12021 (29.8\%) (2000) and 3140 of 11328 (27.7\%) (2001) urine cultures were positive for significant bacterial growth. E. coli isolates were $32.4 \%(2000)$ and $37.4 \%$ (2001) of the total microorganisms isolated. The ratio of $E$. coli isolates for outpatients (community-acquired) to inpatients was approximately $3: 1$ in both years (Table $1)$. The ratio of male patients to female patients was 1:4.

Table 2 shows the antimicrobial susceptibility patterns of $2335 \mathrm{E}$. coli isolates from inpatients and outpatients as well as

\begin{tabular}{|c|c|c|c|c|}
\hline \multirow{2}{*}{ Variable } & \multicolumn{2}{|c|}{2000} & \multicolumn{2}{|c|}{2001} \\
\hline & No. & $\%$ & No. & $\%$ \\
\hline rine & 12021 & 100 & 11328 & 100 \\
\hline ositive cultures & 3583 & 29.8 & 3140 & 27.7 \\
\hline co & 1160 & 32. & 1175 & 37.4 \\
\hline & & 72. & 820 & $69 . \varepsilon$ \\
\hline Inpatients & 317 & $27.3^{\mathrm{a}}$ & 355 & $30.2^{\mathrm{a}}$ \\
\hline
\end{tabular}

The ratio of male patients to female patients was 1:4 throughout the 2-year study.

${ }^{a}$ As $\%$ of total $\mathrm{E}$. coli isolates. the overall susceptibility rates. The rates of resistance to amoxicillin/clavulanate nalidixic acid, gentamicin, norfloxacin, cefuroxime and nitrofurantoin in isolates from inpatients were significantly greater $(P<0.05)$ than for isolates from outpatients.

Table 3 shows the 12 resistance phenotypes of 53 randomly selected multiresistant $E$. coli isolates. Resistance phenotype of 4-drugs (AGmTTs) accounted for almost half these isolates $(26 / 53,49 \%)$. Other resistance phenotypes were less common and ranged between $2 \%$ and $9 \%$. The $\mathrm{MIC}_{90}$ of 20 multiresistant $E$. coli isolates (resistant to 4 drugs or more) were: ampicillin $>128 \mathrm{mg} / \mathrm{L}$, cotrimoxazole $>128 \mathrm{mg} / \mathrm{L}$, tetracycline $>32 \mathrm{mg} / \mathrm{L}$, gentamicin $>16 \mathrm{mg} / \mathrm{L}$ and nalidixic acid $>8$ $\mathrm{mg} / \mathrm{L}$ (Table 2).

Table 3 also shows transferable resistance and plasmid profiles of 16 multiresistant E. coli strains, and $15 E$. coli transconjugants strains. The results showed 13 different plasmid profiles associated with 12 resistance phenotypes and plasmid sizes ranged from $2.0 \mathrm{~kb}$ (kilobases) to $59.4 \mathrm{~kb}$. A common large plasmid $(28.0 \mathrm{~kb})$ with similar digest patterns to Hind III restriction enzyme was in 10 of 15 E. coli donor strains $(67 \%)$ with mostly similar antimicrobial resistance patterns. Also, 11 of 15 E. coli strains (73\%) contained more than 1 plasmid, but no isolate contained more than 6 plasmids. Rplasmids were detected in E. coli isolates from both hospitalized patients (7) and non-hospitalized patients (6) with nearly similar rates ( $47 \%$ and $53 \%$ respectively).

\section{Discussion}

The prevalence of uropathogens and their susceptibility to certain antimicrobial drugs has been reported in a few studies in Jordan

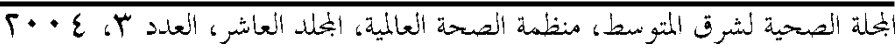



Table 2 Antimicrobial susceptibility rates of 2335 E. coli isolates
from urine cultures of inpatients and outpatients during 2000-
2001 at Jordan University Hospital

\begin{tabular}{|c|c|c|c|c|}
\hline \multirow{2}{*}{$\begin{array}{l}\text { Antimicrobial } \\
\text { agent }\end{array}$} & \multicolumn{3}{|c|}{ Susceptible isolates (\%) } & \multirow[b]{2}{*}{$\begin{array}{l}M I C_{90} \\
(m g / L)\end{array}$} \\
\hline & $\begin{array}{c}\text { Inpatients } \\
(n=667)\end{array}$ & $\begin{array}{c}\text { Outpatients } \\
(n=1663)\end{array}$ & $\begin{array}{c}\text { Total } \\
(n=2335)\end{array}$ & \\
\hline Ampicillin & 10 & 12 & 11 & $>128$ \\
\hline Cotrimoxazole & 24 & 22 & 23 & $>128$ \\
\hline Tetracycline & 27 & 25 & 26 & $>32$ \\
\hline $\begin{array}{l}\text { Amoxicillin/ } \\
\text { clavulanate }\end{array}$ & 21 & 45 & 33 & - \\
\hline Nalidixic acid ${ }^{b}$ & 37 & 68 & 53 & $>8$ \\
\hline Gentamicin ${ }^{\mathrm{b}}$ & 34 & 70 & 52 & $>16$ \\
\hline Norfloxacin ${ }^{b}$ & 41 & 81 & 61 & - \\
\hline Cefuroxime $^{b}$ & 47 & 83 & 65 & - \\
\hline Nitrofurantoin ${ }^{\mathrm{b}}$ & 58 & 94 & 76 & - \\
\hline
\end{tabular}

${ }^{a}$ Approximately $1 \%$ of isolates were recorded.

${ }^{b} \mathrm{P}$-value $\leq 0.05$; significant between total inpatients and outpatients. ${ }^{c}$ MICs of 20 multiresistant (> 4 drugs) E. coli strains.

$M I C=$ minimum inhibitory concentration.

over the last 2 decades [20-24]. These studies, which covered major regions of the country over a period of 21 years (1978-1999), showed that $42 \%-82 \%$ of all positive urine cultures were E. coli and that community-acquired urinary tract infections were mostly caused by E. coli $(75 \%-$ $82 \%)$. These studies along with our 2-year study (2000-2001) demonstrated that uropathogenic E. coli isolates were highly resistant to ampicillin ( $82 \%-95 \%)$, tetracycline $(83 \%-86 \%)$ and cotrimoxazole (48\%-77\%). In addition, moderate to high rates of resistance to other commonly prescribed antibiotics in our country have recently developed. Examples include cefuroxime and norfloxacin in uropathogenic E. coli isolates, as demonstrated in our study.

A comparison of antibiotic-resistance patterns of uropathogenic E. coli isolates in
1978 and 2000-2001 in the same hospital (Jordan University Hospital, Amman) revealed that gentamicin resistance increased significantly $(P<0.05)$, from $13 \%$ to $48 \%$, nalidixic acid resistance increased from $16 \%$ to $47 \%$, and resistance rates to cotrimoxazole, ampicillin and tetracycline were very high $(48 \%-83 \%)$ in 1978 and remained high throughout the 23-year period. Nitrofurantoin resistance increased slightly, from $14 \%$ to $24 \%$ [24]. In our study, however, a significantly higher rate of resistance to amoxicillin/clavulanate, nalidixic acid, gentamicin, norfloxacin, cefuroxime and nitrofurantoin was detected in urinary $E$. coli strains from hospitalized patients than strains from outpatients $(P<0.05)$. In a 1997 study at our hospital, there was a slight increase in the incidence of $E$. coli resistance to extended-spectrum $\beta$-lactam drugs over a period of 3 years, but there

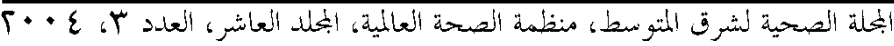




\begin{tabular}{|c|c|c|c|c|c|c|}
\hline \multicolumn{2}{|c|}{ No. of strains } & \multirow{2}{*}{$\begin{array}{l}\text { Resistance } \\
\text { phenotype }^{a}\end{array}$} & \multicolumn{2}{|c|}{ Transferable resistance } & \multicolumn{2}{|c|}{ Plasmid profile (kb) } \\
\hline Donor & Recipient & & Phenotype & $\begin{array}{l}\text { No. of } \\
\text { strains }\end{array}$ & Donor & Recipient \\
\hline 1 & 1 & ACxmGmNaNorTTs & AGmNorTTs & 1 & $\begin{array}{c}12.2,7.4 \\
6.6,3.0\end{array}$ & 7.4 \\
\hline \multirow[t]{2}{*}{2} & 1 & ACxmGmNiTTs & ACxmNiTs & 1 & 28.0 & 28.0 \\
\hline & & ACxmGmNiTTs & - & - & $\begin{array}{c}59.4,48.2 \\
40.0,28.0 \\
6.4,2.2\end{array}$ & - \\
\hline \multirow[t]{2}{*}{4} & 2 & ACxmGmTTs & ACxmGmTs & 1 & 29.2 & 29.2 \\
\hline & & ACxmGmTTs & $A$ & 1 & $\begin{array}{c}48.0,28.0 \\
3.9,3.2,2.12\end{array}$ & $48.0,28.0$ \\
\hline 1 & 0 & AGmNiTTs & - & - & - & - \\
\hline 1 & 1 & ACxmGmTs & AGm & 1 & $\begin{array}{c}47.4,28.0 \\
10.4,6.0 \\
3.03,2.0\end{array}$ & $47.4,28.0$ \\
\hline \multirow[t]{6}{*}{26} & 7 & AGmTTs & ATTs & 2 & $\begin{array}{c}45.4,42.4 \\
26.6,2.8\end{array}$ & $\begin{array}{c}45.4,42.4 \\
26.6\end{array}$ \\
\hline & & & & & 28.0 & 28.0 \\
\hline & & AGmTTs & AGmTs & 1 & $28.0,6.6,4.4$ & $28.0,6.6,4.4$ \\
\hline & & AGmTTs & $\mathrm{Gm}$ & 2 & $\begin{array}{c}49.8,29.2,4.0,3.2 \\
28.0,11.2 \\
6.2,3.0,2.2\end{array}$ & $\begin{array}{c}49.8,29.2 \\
28.0\end{array}$ \\
\hline & & AGmTTs & $A$ & 2 & $28.0,7.0$ & 28.0 \\
\hline & & & & & $28.0,18.0$ & 18.0 \\
\hline 1 & 1 & ACxmGmT & $A$ & 1 & $29.2,25.4$ & $29.2,25.4$ \\
\hline 1 & 1 & ACxmTTs & ACxm & 1 & 28.0 & 28.0 \\
\hline 5 & 1 & ATTs & ATTs & 1 & 28.0 & 28.0 \\
\hline 5 & 0 & AGmT & - & - & - & \\
\hline 4 & 0 & AGmTs & - & - & - & \\
\hline 2 & 0 & ACxmTs & - & - & - & \\
\hline 53 & 15 & - & - & - & - & \\
\hline
\end{tabular}

${ }^{a} A=$ ampicillin, $C x m=$ cefuroxime, $\mathrm{Gm}=$ gentamicin, $T=$ tetracycline, $T s=$ cotrimoxazole, Nor $=$ norfloxacin, $\mathrm{Ni}=$ nitrofurantoin

was a significant increase in the resistance of Klebsiella pneumoniae to ceftazidime and aztreonam among patients in intensive care units [25].
Recent studies published in Europe and North America during the past 3 years have demonstrated an increasing antibiotic resistance among uropathogenic $E$. coli isolated

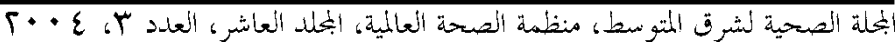


from either community or hospitalized patients. In particular, increased resistance up to $37 \%$ to various penicillins, cephalosporins and cotrimoxazole have been reported in uropathogenic $E$. coli in certain countries $[2,4-6,12,14]$. Although most of these studies have observed low rates of fluoroquinolone resistance in uropathogenic $E$. coli $(2 \%-12 \%), 2$ studies from Spain have recently reported that $22 \%-27 \%$ of uropathogenic $E$. coli strains were resistant to ciprofloxacin $[4,11]$. In our study plasmid analysis of representative $E$. coli isolates showed the presence of a wide range of plasmid sizes, and there were no consistent relationships between plasmid profiles and resistance phenotypes. Partial resistance was mostly transferred in association with a common large plasmid of molecular size $28 \mathrm{~kb}$. The frequency of conjugative Rplasmids was high in association with resistance to 3-7 drugs in E. coli strains. These R-plasmids were found in E. coli isolates from both hospitalized patients and non-hospitalized patients at similar rates (47\% and 53\% respectively).

In conclusion, the results of our study indicate a high-level of antimicrobial resistance to drugs commonly prescribed for urinary tract infections (including norfloxacin) in uropathogenic E. coli isolates in Jordan, particularly in hospitalized patients. Additionally, the common presence of transferable R-plasmids in these $E$. coli isolates is a potential reservoir for the spread of multiple antibiotic resistance in our Region.

\section{Acknowledgements}

We wish to thank our colleagues at the bacteriology laboratory, Jordan University Hospital in Amman for their support in collecting the urine culture results and the $E$. coli isolates.

This work was supported by a grant from the Deanship of Postgraduate Studies, University of Jordan.

\section{References}

1. Stamm WE, Norrby SR. Urinary tract infections: disease panorama and challenges. Journal of infectious diseases, 2001, 183:S1-4.

2. Mathai $D$ et al. Epidemiology and frequency of resistance among pathogens causing urinary tract infections in 1510 hospitalized patients: A report from the Sentry Antimicrobial Surveillance Program (North America). Diagnostic microbiology and infectious disease, 2001, 40:129-36.

3. Goldstein FW. Antibiotic susceptibility of bacterial strains isolated from patients with community-acquired urinary tract infections in France. European journal of clinical microbiology and infectious disease, 2000, 19:112-7.
4. Daza R et al. Antibiotic susceptibility of bacterial strains isolated from patients with community-acquired urinary tract infections. International journal of antimicrobial agents, 2001, 18:211-5.

5. Gupta $\mathrm{K}$ et al. Increasing antimicrobial resistance and the management of uncomplicated community-acquired urinary tract infections. Annals of internal medicine, 2001, 135:41-50.

6. Fluit $A C$ et al. Antimicrobial resistance among urinary tract infection (UTI) isolates in Europe: results from the Sentry Antimicrobial Surveillance Program 1997. Antonie Van Leeuwenhoek, 2000, 77:147-52.

7. Sotto A et al. Risk factors for antibioticresistant Escherichia coli isolated from

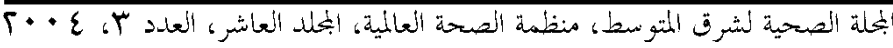


hospitalized patients with urinary tract infections: a prospective study. Journal of clinical microbiology, 2001, 39:438-44.

8. Nicolle LE. Urinary tract pathogens in complicated infection and in elderly individuals. Journal of infectious diseases, 2001, 183:S5-8.

9. Wagenlehner FME, Naber RG. Hospitalacquired urinary tract infections. Journal of hospital infection, 2000, 46:171-81.

10. Manges AR et al. Widespread distribution of urinary tract infections caused by a multidrug-resistant Escherichia coli clonal group. New England journal of medicine, 2001, 345:1007-13.

11. Bukharie HA, Saeed IM Antimicrobial resistance among pathogens causing acute uncomplicated UTIs. Infections in medicine, 2001, 18:358-62.

12. Chomarat M. Resistance of bacteria in urinary tract infections. International journal of antimicrobial agents, 2000, 16: 483-7.

13. Goettsch W et al. Increasing resistance to fluoroquinolones in Escherichia coli from urinary tract infections in the Netherlands. Journal of antimicrobial chemotherapy, 2000, 46:223-38.

14. Jones RN et al. Characteristics of pathogens causing urinary tract infections in hospitals in North America: results from the Sentry Antimicrobial Surveillance Program, 1997. Diagnostic microbiology and infectious disease, 1999, 35:55-63.

15. Murray PR et al., eds. Manual of clinical microbiology, 6th ed. Washington DC, American Society for Microbiology, 1995.

16. Methods for dilution antimicrobial susceptibility tests for bacteria that grow aerobically. Approved standard M7-A4, 3rd ed. Villanova, Pennsylvania, National Committee for Clinical Laboratory Standards, 1997.
17. Silva $\mathrm{J}$ et al. A new plasmid-mediated extended-spectrum $\beta$-lactamase from Escherichia coli. Antimicrobial agents and chemotherapy, 2000, 44:997-1003.

18. Shehabi AA. Extra-intestinal infections with multiple drug-resistant Salmonella typhimurium in hospitalized patients in Jordan. European journal of clinical microbiology and infectious disease, 1995, 14:448-51.

19. Birnboim HC, Doly J. A rapid alkaline extraction procedure for screening recombinant plasmid DNA. Nucleic acids research, 1979, 7:1513-23.

20. Abu Shaqra $Q$. Occurrence and antibiotic sensitivity of Enterobacteriaceae isolated from a group of Jordanian patients with community acquired urinary tract infections. Cytobios, 2000, 101:1521.

21. Abu-Elteen $\mathrm{K}$ et al. Antibiotic resistance of bacteria isolates from urine specimens in Amman. Jordan medical journal, 2000, 34:117-22.

22. Malkawi HI, Youssef MT. Characterization of $E$. coli isolated from patients with urinary tract infections in Northern Jordan: Antibiotic resistance and plasmid profiles. Mu'tah journal of research and studies, 1997, 11:171-92.

23. Farah N. A study of urinary tract pathogens and their antimicrobial sensitivities. Jordan medical journal, 1994, 28:1338.

24. Shehabi AA. Antimicrobial susceptibility pattern of bacteria commonly isolated from urine at the Jordan University Hospital, 1980, Dirasat, 7:25-30.

25. Shehabi AA et al. High incidence of Klebsiella pneumoniae clinical isolates to extended-spectrum $\beta$-lactam drugs in intensive care units. Diagnostic microbiology and infectious disease, 2000, 36: 53-6.

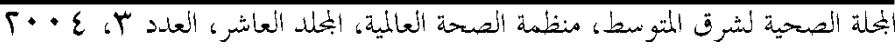

